Tohoku J. exp. Med., 1979, 129, 83-90

\title{
Improved Oral Excretory Cholecystocholangiography
}

\author{
ShinjI NiIzuma \\ Department of Radiology, Niigata Cancer Hospital, Niigata 951
}

\begin{abstract}
Nitzuma, S. Improved Oral Excretory Cholecystocholangiography. Tohoku J. exp. Med., 1979, 129 (1), 83-90 — A new improved technique for the visualization of intrahepatic bile ducts with oral contrast agent has been developed. The right lateral decubitus position was employed to avoid drainage of contrast medium from the common bile duct into the duodenum. $0.2-0.3 \mu \mathrm{g} / \mathrm{kg}$ of Caerulein was injected intramuscularly (350 cases) or $0.02 \mu \mathrm{g} / \mathrm{kg}$ of Kinevac was injected intravenously ( 15 cases) to induce rapid contraction of the gallbladder. The extruded contrast medium, which would normally flow into the duodenum, flowed backward into the intrahepatic bile ducts due to gravity. With this technique, improved visualization of intrahepatic bile ducts was achieved with use of oral contrast medium; it also obviated the problem of colonic gas over. lapping the gallbladder and gallstones in cholecystography. ___ oral cholecystocholangiography; Caerulein; lateral decubitus position
\end{abstract}

Since the development of excretory cholecystography by Graham and Cole in 1924, progresses and improvements have been made by: (1) newer contrast media resulting in greater degree of opacification and decreased incidence of adverse reactions, (2) improved opacification by increased doses of contrast medium, for example the double dose method (Salzman and Warden 1958) and drip infusion cholecystography (Dijan and Annonier 1964).

Improved opacification may also be achieved by delaying the drainage of contrast medium. In excretory urography, Trendelenburg positioning is used effectively to delay the evacuation of contrast medium by gravity. We have attempted to utilize this same principle in oral cholecystography.

\section{Methods}

Various positions were tested for the radiographic examination of the gallbladder. It was found that in the right lateral decubitus position, with slightly head down $(6-8$ degrees), the gallbladder, hepatic ducts, and common bile duct were in a dependent position relative to the duodenum. Moreover, patients could comfortably remain in this position for the duration of the examination. Since August 1975 until December 1977, 365 examinations had been performed in a right lateral decubitus position with a horizontal $\mathrm{x}$-ray beam device.

At first, a fatty meal was employed to evacuate the contrast medium from the gallbladder and it required 20 to $30 \mathrm{~min}$ during which the patients were very uncomfortable. An intramuscular injection of $0.2-0.3 \mu \mathrm{g} / \mathrm{kg}$ of Caerulein made the evacuation much faster and it completed in 5 to $15 \mathrm{~min}$. Films were usually exposed at about 7 to $12 \mathrm{~min}$ after injection. Due to the effect of gravity, the evacuated contrast medium flowed into

Received for publication, September 21, 1978. 
intrahepatic bile ducts rather than into the duodenum. When the patient's position was changed to supine or prone, almost immediate drainage of contrast medium occurred from the hepatic ducts into the duoenum. We therefore radiographed the patient in the right lateral decubitus position with a cross table horizontal beam. In this position, the gallbladder was often seen at the level of the eleventh or twelfth thoracic vertebral body, that is higher than usual, and thus might be overlapped by the ribs or calcifications of the cartilages. For this reason, we often employed tomography as a part of our present method of cholecystography. Moreover, it is well known that tomography has decisive diagnostic value in many cases of cholecystography. This was accomplished in the right lateral projection with a specially constructed apparatus with TV and tomography (Fig. 1). As for the contraction ratio in the entire cases, three films taken before Caerulein injection, and about 7 and 12 min thereafter were measured with a planimeter and the ratio was calculated by the following formula:

$$
\frac{\text { area before injection }- \text { area after injection }}{\text { area before injection }} \times 100 .
$$

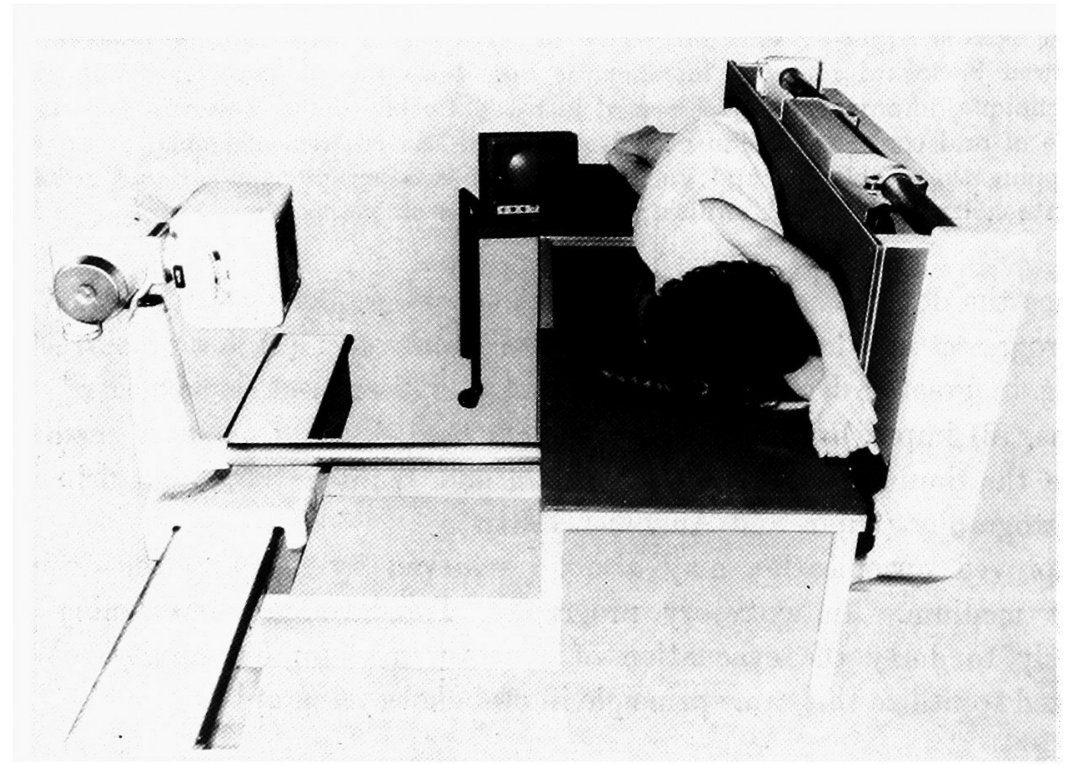

Fig. 1. x-Ray TV apparatus to check the position and contracting size of the gallbladder.

Right lateral decubitus position with horizontal x-ray beam and tomography available.

\section{Results}

365 examinations were performed utilizing our modified peroral cholecystographic method. The results are shown in Table 1 . When opacification of the gallbladder was not achieved with oral contrast media, intravenous cholangiography was employed. The incidence of these cases were $3.5 \%$ in our clinic. These cases were not included in the present study.

In $128(35.1 \%)$ cases, small intrahepatic ducts were visualized; i.e., ventrocranial duct, and dorsocaudal duct (Figs. 2, 3). The biliary system just proximal to the junction of the right and left hepatic ducts was visualized in $135(36.9 \%)$ cases. However, since these ducts were also seen in those cases in which small 
TABLE 1. Visualization rate of biliary system with peroral contrast medium

\begin{tabular}{|c|c|c|c|}
\hline & Numbe & er of cases & Total number of cases \\
\hline & & $\%$ & $\%$ \\
\hline $\begin{array}{l}\text { Small hepatic ducts } ~ \\
\text { common bile duct }\end{array}$ & 128 & $(35.1)$ & \\
\hline $\begin{array}{l}\text { Right and left hepatic ducts } \\
\sim \text { common bile duct }\end{array}$ & 135 & (36.9) & $263(72.1)$ \\
\hline $\begin{array}{l}\text { Common hepatic duct } ~ \\
\text { common bile duct }\end{array}$ & & (10.4) & $301 \quad(82.5)$ \\
\hline $\begin{array}{l}\text { Cystic duct and } \\
\text { common bile duct }\end{array}$ & 32 & (8. 8) & $333(61.2)$ \\
\hline Gallbladder only & 32 & ( 8.8$)$ & $365(100)$ \\
\hline
\end{tabular}

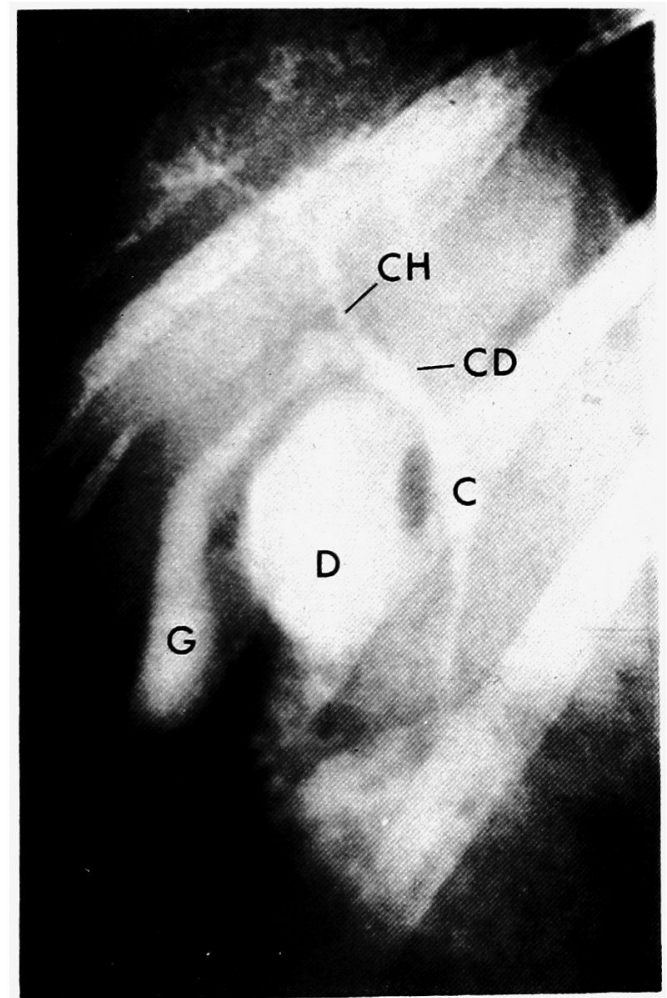

Fig. 2

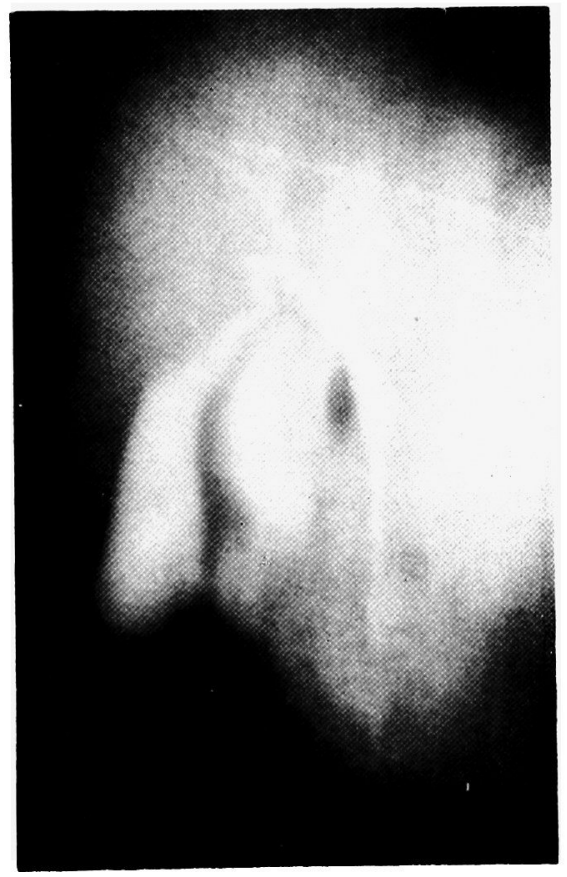

Fig. 3

Fig. 2. Cholecystocholangiography with peroral contrast medium and Caerulein injection in right lateral decubitus position. C, ductus choledochus; $\mathrm{CD}$, cystic duct; $\mathrm{CH}$, common hepatic duct; $\mathrm{D}$, duodenal cap; $\mathrm{G}$, gallbladder.

Fig. 3. Tomography in the same case as Fig. 2. 
hepatic ducts were visualized, the total number was brought up to 263 cases $(72.1 \%)$. Visualization of the hepatic duct and the common bile duct alone was achieved in 38 $(10.4 \%)$ cases. Visualization of only the cystic duct and common bile duct was achieved in $32(8.8 \%)$. But the visualization ratio of the common bile duct reached 333 cases of the total of 365 cases $(91.2 \%$ ). This ratio was higher than that of the previous observation. In our conventional previous procedures with fatty meal (300 cases), the common bile duct could be observed only in $38.0 \%$ of the entire cases, and the common hepatic duct and other small intrahepatic ducts were in $0 \%$. In $32(8.8 \%$ ) cases, visualization of the duct system was not achieved. In these 32 patients, the gallbladder failed to contract following injection of Caerulein, or the rate of contraction was less than $20 \%$ as measured by a planimeter. Analytical studies were then made on such cases in which the common bile duct was not opacified. (Table 2) Poor contraction was encountered mainly in obese patients.

An additional advantage of the right lateral decubitus position was an increased rate of the detection of gallstones. This was due to the elimination of colonic gas overlap in this position, as shown in Fig. 4 and Table 3. Besides, in the upright position stones were situated in the bottom of gallbladder, but in the right lateral

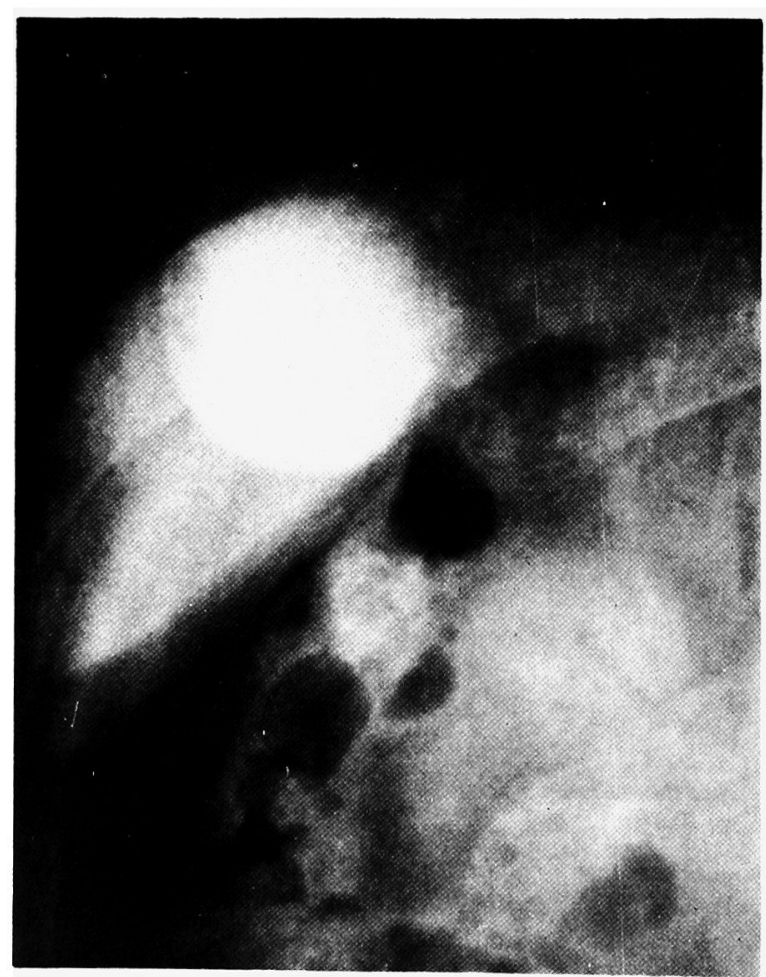

Fig. 4. Gallstones are visualized in the dependent side of the gallbladder; overlapping of colonic gas shadow has been eliminated. 
TABLE 2. Reasons of non-visualized common bile duct

$\begin{array}{lr}\text { Poor contraction of gallbladder } & 17 \\ \text { Under exposure due to obesity } & 4 \\ \text { Flowing out of supernatant, thin contrast } & 3 \\ \quad \text { medium from gallbladder } & \\ \text { Poorly visualized gallbladder } & 2 \\ \text { Improper posture } & 1 \\ \text { Obstruction caused by gallstone } & 1 \\ \text { Excessive contraction } & 1 \\ \text { Unknown reason } & 3 \\ \quad \text { Total } & 32\end{array}$

TABLE 3. Overlapping of shadow of gallbladder and colonic gas

\begin{tabular}{ccc}
\hline & Upright position & Right lateral position \\
\hline & $\%$ & $\%$ \\
Overlapping $(+)$ & $92(65.7)$ & $21(15.0)$ \\
Overlapping $(-)$ & $48(34.3)$ & $119(85.0)$ \\
\hline
\end{tabular}

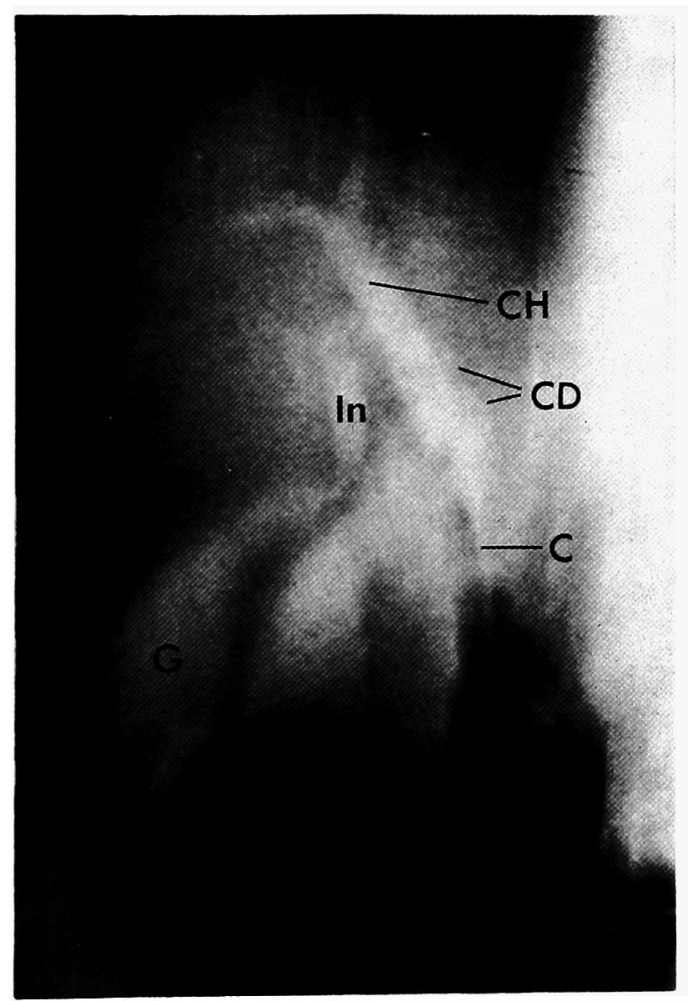

Fig. 5. Two gallstones are visualized in the common hepatic duct with peroral contrast medium. C, ductus choledochus; CD, cystic duct; $\mathrm{CH}$, common hepatic duct; G, gallbladder; In, infundibulum. 
position they moved to the right side of the gallbladder, therefore overlapping of stones and colonic gas was rarely encountered.

\section{Discussion}

Two methods have been reported in the literature, dealing with improved opacification of the bile ducts by preventing the outflow of contrast medium. The first was made by Lura and Vivarelli (1955), in which an inflatable balloon was inserted into the duodenum to occlude the region of the papilla of Vater. The second was the method of Cohn et al. (1955), in which contraction of the sphincter of Oddi was achieved by administration of morphine in 2 cases. However, these methods have not been widely utilized in routine clinical investigations.

By our method, in which the gallbladder and common bile duct were in a dependent position relative to the duodenum, drainage of contrast medium was prevented by gravity. Evacuation of the gallbladder following injection of Caerulein or Kinevac resulted in partial retrograde flow into intrahepatic bile ducts. Consequently, we were able to visualize intrahepatic bile ducts during oral cholecystography.

This oral method opacified successfully the intrahepatic ducts in $72.1 \%$ of the

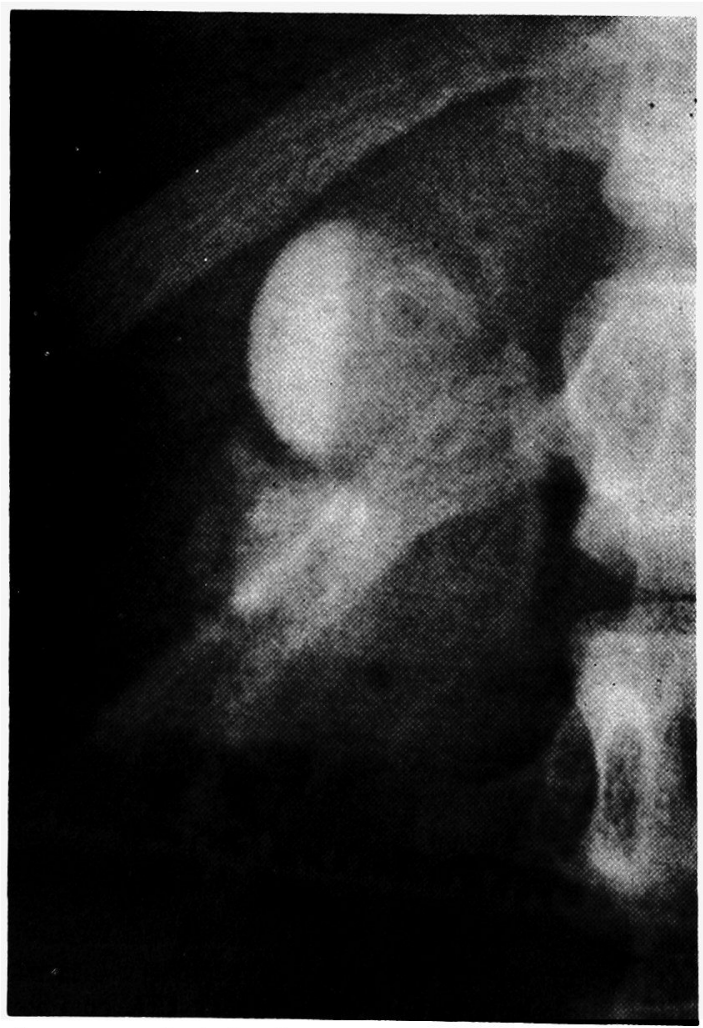

Fig. 6. Adenomyomatosis in the same position with Caerulein injection. 
Table 4. Lesions accidentally discovered

\begin{tabular}{|c|c|c|}
\hline & $\begin{array}{l}\text { Right lateral position } \\
\text { out of } 365 \text { cases }\end{array}$ & $\begin{array}{l}\text { Conventional method } \\
\text { out of } 100 \text { cases }\end{array}$ \\
\hline & \% & $\%$ \\
\hline Cholecystolithiasis & $52(14.3)$ & $12(12.0)$ \\
\hline Calculi in the common hepatic duct & $2(0.5)$ & 0 \\
\hline Polyps & $8 \quad(2.0)$ & 0 \\
\hline Cholesterosis & $4 \quad(1.0)$ & 0 \\
\hline Adenomyomatosis & $2(0.5)$ & 0 \\
\hline Total & $68(18.6)$ & $12(12.0)$ \\
\hline
\end{tabular}

entire cases examined and the common bile duct in $91.2 \%$, more densely than the intravenous method. Its side effects were much less, and it took only a period of $12 \mathrm{~min}$, that is much shorter than $2 \mathrm{hr}$ or more in the intravenous method. Thus the present oral method has a great advantage for clinical purpose. As Table 4 illustrates, the lesions detected by this method were $68(18.6 \%)$ out of 365 cases, while those by the conventional method was $12 \%$ of 100 cases. Two cases of the calculi in the common hepatic duct might not been diagnosed by the conventional oral method out of 54 cholelithiasis cases in our present study. Moreover, many lesions, such as polyps, cholesteroses and adenomyomatoses as small as $\mathbf{3 - 5} \mathbf{m m}$

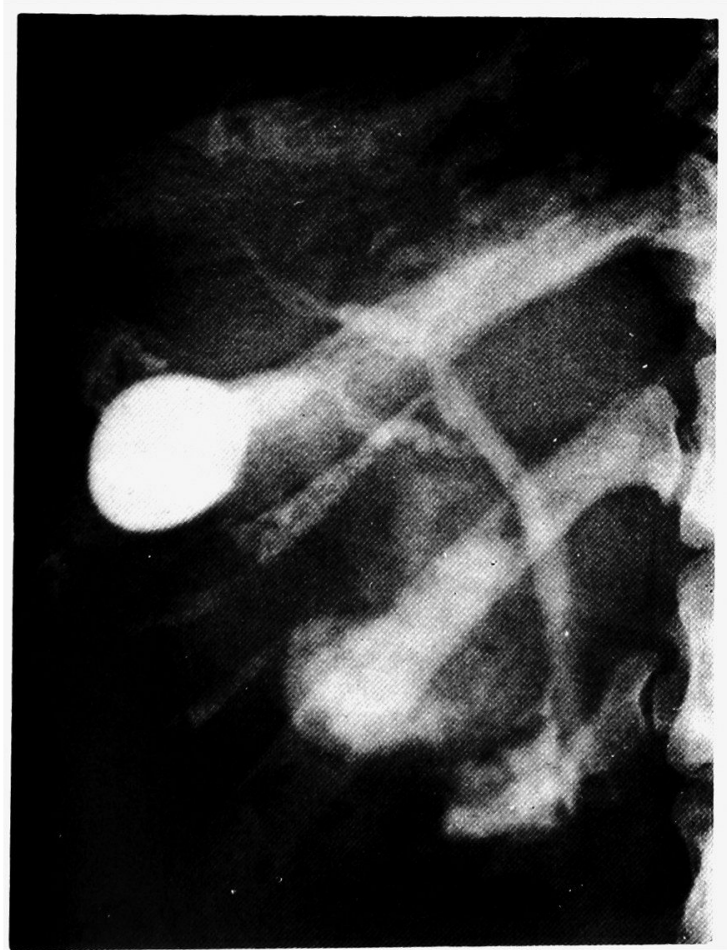

Fig. 7. Heister's spiral valve is clearly visualized by this method. 
in diameter were also found as shown in Figs. 5, 6 and it can be considered as a marked advantage.

In addition, the current method is more physiological than that of direct puncture or endoscopic retrograde cholangiography. This method will be effective for the pathological, physiological and anatomical clarification of the extrahepatic biliary system. As shown in Fig. 7, Heister's spiral valve was clearly observed by this method, but it seldom appeared in the conventional method. And we were able to study separately the contraction in the gallbladder and infundibulum, and, in some cases, narrowness and uneven edge of the intrapancreatic portion of the common bile duct.

\section{References}

1) Cohn, A.F. Orloff, T.L., Sklaroff, O.M. \& Gershen-Cohen, J. (1955) Use of Cholografin in postcholecystectomy syndrome. Ann. intern. Med., 42, 59-68.

2) Dijan, A. \& Annonier, C. (1964) La cholécystocolangiographie immédiate par la méthode de perfusion intraveineuse lente. Semaine des hôspidaux de Paris, 40, 23232328.

3) Graham, E.A. \& Cole, W.H. (1924) Roentgenologic examination of gallbladder: preliminary report of new method of utilizing intravenous injection of tetrabromphenolphalein. J. Amer. med. Ass., 82, 613-614.

4) Lura, A. \& Vivarelli, A. (1955) Nuovo metodo di esplorazione delle vie biliare: cholangiocholecistografia bloccata. Radiol. Med., 41, 945-958.

5) Salzman, E. \& Warden, M.R. (1958) Telepaque opacification of radiolucent biliary calculi, the "Rim sign". Radiology, 71, 85-89. 